\title{
Eksplorasi Etnomatematika Pada Candi Muara Takus Di Kec. XIII Koto Kampar Riau
}

\author{
Taufik Hidayat ${ }^{1)}$ Ali Asmar $^{2)}$ Yerizon $^{2)}$ \\ ${ }^{1)}$ Program Magister Pendidikan Matematika Pascasarjana Universitas Negeri Padang \\ ${ }^{2}$ Staf Pengajar Program Magister Pendidikan Matematika Pascasarjana Universitas Negeri Padang \\ taufikchaniago.jr@gmail.com \\ aliasmar.sumbar@gmail.com \\ yerizonunp@gmail.com
}

\begin{abstract}
Mathematics has been a part of human culture for a very long time. Many assume that mathe matics is final, permanent, absolute and unrelated to culture. Ethnomatematic is present to bridge be tween culture and education, especially in mathematics learning. One of the ethnomatematic objects is an artifact. Each area certainly has its own culture, including artifacts in the form of historical build ings that are characteristic of the area. Muaro Takus Temple is one of the historical buildings in Kec. XIII Koto Kampar Riau. Muara Takus temple is an ancient religious artifact whose construction is still a mystery has the potential as a source of mathematical learning, but this must go through the exploration process. The purpose of this explorative research with ethnographic approach is to ex plore and explore what mathematical concepts exist in Muaro Takus temple that can be used as a source of mathematics learning as well as an effort to develop ethnomatematics as the basis of mathe matics learning. Through exploration, interviews, documentation, literature studies and observations in the muaro takus temple environment, it can be concluded that there is a concept of square flat buid (square, rectangular, parallel trapezoidal and irregular, rectangle) and triangle (right triangle), circle, reflection \& dilatation, as well as lines and angles on the structure of Muara Takus temple build ing. learning mathematics using ethnomatematic objects can enrich the mathematical applications around students and can facilitate students to understand abstract mathematics by using concrete ethnomatematic objects.
\end{abstract}

Keywords : Ethnomatematics, ExpIoration, Muara Takus temple

This is an open access article distributed under the Creative Commons 4.0 Attribution License, which permits unrestricted use, distribution, and This is an open access article distributed under the Creative Commons 4.0 Attribution License, which permits unrestricted use,
reproduction in any medium, provided the original work is properly cited. $\odot 2018$ by author and Universitas Negeri Padang.

\section{PENDAHULUAN}

Budaya adalah warisan dalam kehidupan masyarakat, dimana budaya itu berkembang me nyesuaikan dengan kondisi yang terjadi dimasa sekarang dan masa yang akan datang. Ini relevan dengan landasan filosofi dalam mengembangkan kurikulum 2013 yaitu, a) Pendidikan berakar pa da budaya bangsa untuk membangun kehidupan bangsa masa kini dan masa mendatang; b) Peser ta didik adalah pewaris budaya bangsa yang kre atif (Permendikbud, 2013).

Pendidikan dan budaya merupakan se suatu yang tidak bisa dihindari dalam kehidupan sehari-hari, karena budaya merupakan kesatuan yang utuh dan menyeluruh, berlaku dalam suatu masyarakat dan pendidikan merupakan kebutuh an mendasar bagi setiap inidividu dalam masya rakat. Pendidikan dan budaya memiliki peran yang sangat penting dalam menumbuhkan dan mengembangakan nilai luhur bangsa kita, yang berdampak pada pembentukan karakter yang di dasarkan pada nilai budaya yang luhur. Penanam an nilai budaya sangat penting untuk mendu kung pembangunan karakter bangsa, karena de ngan pemahaman dan pengaplikasian nilai-nilai budaya individu mampu untuk memfilter penga ruh negatif globalisasi (Wahyuni, dkk; 2013).

Matematika telah menjadi bagian dari kebudayaan manusia sudah sangat lama. Mate matika merupakan bagian dari budaya dan seja rah (Fathani, 2009). Oleh karena itu, pelajaran matematika dapat dikaitkan dengan budaya. Akan tetapi, matematika yang dikonstruksi seba gai bentuk pemikiran rasional tertinggi yang ke mudian dalam pendidikan matematika diajarkan dengan cara yang kaku dimana kontestasi dan perbedaan pendapat ditekan sedemikian rupa se hingga siswa menerima ilmu tersebut begitu saja tanpa ada refleksi kritis (Risdiyanti \& Prahmana, 2020). Sehingga banyak anggapan bahwasannya 
matematika itu bersifat final, permanen, absolut dan tidak berhubungan dengan budaya. Oleh se bab itu, guru harus mampu menunjukkan kepada peserta didik bahwa matematika memiliki hu bungan yang erat dengan budaya dan kehidupan sehari-hari.

Bentuk-bentuk matematika dalam budaya lokal sering dipandang tidak memiliki kontribusi dalam kehidupan moderen pada saat ini, sehing ga keberadaannya diabaikan. Wahyuni, dkk (2013) menyatakan bahwa salah satu yang dapat menjembatani pendidikan dan budaya khusus nya pendidikan matematika adalah etnomatemati ka. D'Ambrosio (1985) memperkenalkan suatu istilah yaitu etnomatematika. Ia mengatakan bah wa matematika yang dibelajarkan di sekolah di sebut dengan academic mathematics, sedangkan etnomatematika merupakan matematika yang di terapkan dalam kelompok budaya yang terdefini si seperti masyarakat suku, kelompok buruh, anak-anak dari kelompok usia tertentu, kelas pro fesional, dan sebagainya. Sehingga dapat dikata kan bahwa etnomatematika merupakan matema tika yang muncul dalam suatu kebudayaan terten tu yang dianggap sebagai lensa untuk meman dang dan memahami matematika sebagai produk budaya.

Pendekatan etnomatematika didefinisikan sebagai penggunaan lingkungan yang dekat dan langsung dari seorang guru dalam mengajar ma tematika (Achor, dkk., 2009). Tanpa disadari ma syarakat telah melakukan berbagai aktivitas de ngan meggunakan konsep dasar matematika dan ide matematis. Mengkaji budaya untuk belajar matematika dengan kata lain menggugah kesa daran bahwa budaya yang kaya merupakan po tensi untuk pembelajaran matematika. Etnomate matika menggunakan konsep matematika secara luas yang terkait dengan berbagai aktivitas mate matika, meliputi aktivitas mengelompokkan, ber hitung, mengukur, merancang bangunan atau alat, bermain, menentukan lokasi, dan lain seba gainya. Menurut Fajriyah (2018) peran etnomate matika juga mendukung literasi matematika de ngan memfasilitasi siswa untuk mampu meng konstruksi konsep matematika sebagai bagian dari literasi matematika berdasarkan pengeta huan siswa tentang lingkungan sosial budaya mereka.

Salah satu cara untuk mengemas agar pem belajaran matematika lebih bermakna yaitu de ngan mengaitkan pada konteks kehidupan di se kitar siswa atau budaya yang sudah mengakar sehingga ini menjadi sesuatu yang konkret dan bermakna di benak siswa (Rahmawati, 2019). Hal ini membuat siswa tidak mudah lupa tentang materi matematika yang telah dipelajarinya dika renakan masalah tersebut sering dijumpainya da lam kehidupan sehari-hari. Selain itu, siswa akan terbiasa untuk mengaitkan setiap materi mate matika dengan budaya yang ada pada kehidupan sehari-hari.

Objek etnomatematika merupakan objek budaya yang mengandung konsep matematika pada suatu masyarakat tertentu. Objek tersebut dapat berupa permainan tradisional, kerajinan tra disional, artefak, dan aktivitas (tindakan) yang berwujud kebudayaan (Hardiarti, 2017). Salah satu artefak berupa bangunan bersejarah yang ada di Riau adalah candi Muaro Takus. Kawasan percandian Muaro Takus terletak di Desa Muara Takus, Kecamatan XIII Koto Kampar, Kabupa ten Kampar, Provinsi Riau atau berjarak $130 \mathrm{~km}$ dari pusat ibukota Provinsi Riau, Pekanbaru. Secara geografis, Muara Takus terletak di tepian Sungai Kampar yang bermuara ke Selat Malaka di timur Pulau Sumatera. Keberadaan gugusan percandian Muara Takus pertama kali dilapor kan oleh Cornet De Groot pada 1860 yang di muat dalam Tijdschrift voor Indische Taal, land en Volkenkunde berjudul Koto Tjandi. Menurut F. M. Schnitger percandian Muara Takus berasal dari kurun abad ke-11 hingga ke-12 M. Candi ini merupakan pusat peribadatan kuno yang di bangun pada saat berkembangnya kebudayaan Klasik Hindu-Buddha di Daerah Aliran Sungai Kampar (Soedewo, dkk; 2015). Percandian Mua ra Takus adalah situs Candi Tertua di Sumatera dan merupakan satusatunya situs bukti sejarah yang berbentuk Candi di Riau.

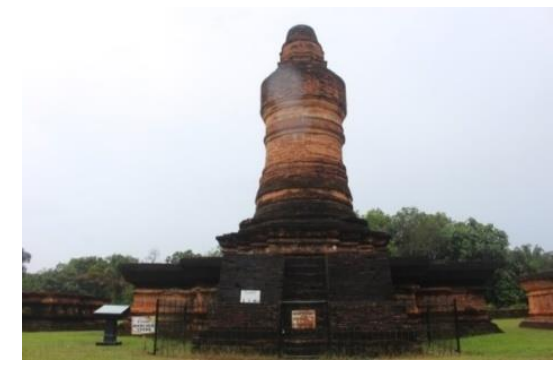

Gambar 1. Candi Mahligai pada kawasan percandian Muara Takus

Kawasan percandian Muara Takus dapat diiden tifikasikan dengan ragam bangunan candi beser ta seluruh fasilitas yang terdapat di dalam nya. 
Dalam hal ini, perwujudannya dapat dibedakan menjadi beberapa bentuk, yaitu 1) Candi Tua; 2) Candi Mahligai; 3) Candi Bungsu; 4) Candi Palangka; 5) Pagar Keliling (Sulistyani, dkk; 2020).

Eksplorasi etnomatematika pada artefak kuno, dilakukan untuk menggali potensi pada artefak itu sendiri yang memuat unsur-unsur dan konsep matematika. Sehingga hasil dari eks plorasi ini dapat digunakan dalam pembelajaran matematika didalam kelas. Eksplorasi unsur -un sur dan konsep matematika yang terdapat pada candi-candi juga pernah dilakukan sebelumnya. Seperti Hardiarti (2017) yang meneliti unsur et nomatematika candi Muaro Jambi yang menya takan terdapat konsep bangun datar segiempat pada beberapa struktur candi Muaro Jambi. Struktur tersebut berbentuk persegi, persegi panjang, jajargenjang, trapesium, dan segiempat tidak beraturan. Lalu, Utami, dkk (2020) yang mengeksplorasi unsur ernomatematika di candi Borobudur dimana; (1) Candi Borobudur seba gai produk etnomatematika menyajikan berbagai konsep agama, moral, budaya, dan matematika, (2) Secara keseluruhan, konsep-konsep tersebut memiliki hubungan dan keterkaitan diantara satu sama lain, (3) Konsep-konsep yang disepakati dan diterapkan dalam realita kehidupan, telah membawa matematika sebagai produk budaya yang tertanam sejak zaman dahulu meskipun me reka tidak menyadarinya, dan (4) Candi Borobu dur merupakan contoh monumen dari orkesta matematika dalam bentuk etnomatematika. Ada juga Jayanti \& Puspasari (2020) yang meneliti unsur etnomatematika pada Candi Sanggrahan Tulungagung, hasil yang diperoleh adalah terda pat kaitan antara Candi Sanggrahan Tulunga gung dan matematika hanya pada bentuk fisik candi. Konsep matematika yang ada di bentuk fisik Candi Sanggrahan Tulungagung adalah geometri bangun datar, bangun ruang, garis dan sudut, kesebangunan dan kekongruenan, dan ju ga transformasi geometri. Pembelajaran matema tika menggunakan objek etnomatematika dapat memperkaya aplikasi matematika yang ada di sekitar siswa serta dapat memfasilitasi siswa memahami matematika yang bersifat abstrak de ngan menggunakan objek etnomatematika yang konkret. Selain itu siswa juga dapat mempelajari sejarah kebudayaan yang terdapat disekitarnya, sehingga kebudayaan itu selalu diwariskan dan tidak akan pernah dilupakan keberadaannya karena menjadi bagian kekayaan potensi luhur di sekitar siswa.

Candi Muara Takus sebagai salah satu ar tefak kuno peninggalan zaman kejayaan pera daban buddhis di Kec. XIII Koto Kampar Pro vinsi Riau masih menyimpan potensi besar un tuk menjadi sumber pembelajaran matematika. Dengan mengeksplorasi candi Muara Takus, di harapkan dapat menguak unsur-unsur dan kon sep matematika apa saja yang terdapat disana. Sehingga dapat dipergunakan untuk bahan pem belajaran matematika didalam kelas.

Berdasarkan uraian di atas mengenai keter kaitan matematika dan budaya dan potensi buda ya dalam pendekatan pembelajaran matematika, maka penelitian yang bertujuan untuk menggali etnomatematika pada Candi Muaro Takus menja di perlu dan penting untuk dilakukan.

\section{METODE PENELITIAN}

Jenis penelitian ini adalah penelitian eks ploratif. Arikunto (2013) menjelaskan "peneliti an eskploratif merupakan penelitian yang bertu juan untuk menggali secara luas tentang sebabsebab atau hal-hal yang mempengaruhi terjadi nya sesuatu". Sedangkan pendekatan yang digu nakan dalam penelitian ini adalah pendekatan et nografi yaitu pendekatan yang bertujuan menye lidiki dan mendapatkan deskripsi serta analisis mendalam tentang suatu kelompok kebudayaan berdasarkan penelitian lapangan (fieldwork) da lam periode waktu tertentu secara intensif. Pen dekatan ini memusatkan usaha untuk menemu kan bagaimana masyarakat mengorganisasikan budaya tersebut dalam pikiran mereka dan kemu dian menggunakannya dalam kehidupan sehing ga ada dalam pikiran manusia. Metode peneli tian yang dilakukan adalah observasi, wawan cara, dokumentasi dan studi literatur. Penelitian dilaksanakan di Candi Muara Takus di Kec. XIII Koto Kampar dan Balai Pelestarian Cagar Bu daya Provinsi Sumatera Barat. Peneliti meneliti tentang konsep matematika pada Candi Muara Takus. Penelitian ini diawali dengan melakukan survei di tempat dilakukannya penelitian, penyu sunan instrumen penelitian (berupa lembar obser vasi, pedoman wawancara semi berstruktur dan lembar analisis etnomatematika) menentukan jadwal penelitian, dan proses pelaksanaan peneli tian. Pada dasarnya data yang akan dianalisis da lam penelitian ini berdasarkan hasil observasi, 
wawancara, dan dokumentasi yang mengaitkan bagaimana budaya yang terdapat di Candi Mua ra Takus mengandung unsur matematika. Selan jutnya studi literatur dilakukan untuk mengana lisis konsep matematika pada candi Muaro Ta kus. Pada tahap observasi, peneliti mengamati bangunan-bangunan kuno di areal perkomplekan candi Muara Takus. Pada tahap wawancara, pe neliti mewawancarai pengawas lapangan serta tokoh budayawan setempat mengenai sejarah awal ditemukannya candi, tujuan dan fungsi pen dirian candi, arti dari masing-masing bangunan candi, pemugaran dan bentuk-bentuk candi serta proses dan bahan dasar untuk pembangunan can di Muara Takus. Di tahap dokumentasi, peneliti mendokumentasikan bagian-bagian bangunan yang diamati mengandung konsep matematika untuk dilakukan analisis domain. Dan terakhir ditahap studi literatur, peneliti mengumpulkan data-data mengenai Candi Muara Takus dengan mengunjungi Balai Pelestarian Cagar Budaya Provinsi Sumatera Barat yang memuat bukubuku sejarah Candi Muara Takus dan buku me ngenai pemugaran Candi Muara Takus. Selain itu, peneliti juga mengumpulkan referensi jurnal mengenai etnomatika pada candi-candi yang ada di Indonesia.

\section{HASIL DAN PEMBAHASAN}

Berdasarkan hasil eksplorasi, pengamat an dan dokumentasi, candi Muaro Takus memi liki beberapa bentuk konsep matematika. Dalam pembahasan ini disajikan bentuk matematika pa da candi Muaro Takus, dan konsep matematika yang menjelaskan bentuk-bentuk tersebut. Berda sarkan hasil wawancara diketahui bahwa Candi Muara Takus merupakan bangunan cagar buda ya yang banyak dinyatakan bernuansa Buddhis. Penelitian R.D.M Verbeck dan E.Th. Van Del den bangunan candi ini diduga merupakan ba ngunan suci agama Budha yang berbentuk biara dan ruangan. Muara Takus berasal dari nama se buah anak sungai kecil bernama takus, anak su ngai takus bermuara ke batang kampar kanan. Situs candi Muara Takus dikelilingi oleh tembok yang berbentuk bujur sangkar, di luar arealnya terdapat pula tembok tanah berukuran $1,5 \mathrm{~km} x$ $1,5 \mathrm{~km}$, mengelilingi kompleks ini sampai ke pinggir Sungai Kampar Kanan. Menurut para ah li, jumlah candi keseluruhan berjumlah tujuh buah, sedangkan di kawasan Candi Muara Takus baru terdapat empat gugusan candi yang baru di jumpai yaitu Candi Tua, Candi Bungsu, Mahli gai dan Palangka.

Berdasarkan hasil wawancara, dapat dii dentifikasi bangunan-bangunan yang terdapat di kompleks percandian Muara Takus diantaranya: 1) Candi Tua

Candi Tua merupakan bangunan yang terbe sar di dalam kompleks percandian Muara Ta kus. Bangunan ini nyaris menempel di sisi utara Candi Bungsu dengan jarak hanya se kitar $22 \mathrm{~cm}$. Bangunan Candi Tua menjadi ba ngunan utama pertama yang ditemui jika wi satawan masuk melalui pintu loket juru peli hara. Wujud bangunan utuh dan selesai dipu gar. Struktur kaki bangunan hasil pemugaran memiliki wujud empat persegi panjang pada tingkat I dengan banyak penampil. Jumlah su dut luarnya adalah 24 buah, termasuk sudut tangga naik. Bangunan ini memiliki dua (2) buah tangga naik di sisi Barat dan di sisi Ti mur untuk mencapai puncak stupa.

2) Candi Mahligai

Stupa Mahligai berbentuk bangunan tinggi, menghadap ke arah gerbang masuk di sisi Utara kompleks. Letaknya di sekitar $10 \mathrm{~m}$ di sebelah Utara tembok pagar keliling sisi $\mathrm{Ba}$ rat dan di antara Candi Palangka dan Candi Bungsu. Bangunan ini memiliki alas dua (2) buah yang tinggi berukuran 4,10 $\mathrm{m}$ dengan satu (1) tangga naik berukuran lebar $1 \mathrm{~m} . \mathrm{Pa}$ da bagian kaki pertama ditemukan hiasan be rupa pelipit bawah, pelipit padma, pelipit ba dan, dan pelipit atas. Namun, tidak ditemu kan hiasan pada tepi tangga.

3) Candi Bungsu

Candi Bungsu terletak di arah sudut, sekitar 4,80 m arah Barat Candi Mahligai. Bangunan candi ini ditopang oleh tiga (3) kaki pada ba ngunan sisi Utara, dan satu (1) kaki pada ba ngunan sisi Selatan. Bangunan di atas kakikaki ini dibagi menjadi dua (2) bangunan ber dasarkan jenis bahan yang digunakan, yaitu bangunan berbahan bata dan bangunan berba han batu pasir.

4) Candi Palangka

Candi Palangka merupakan bangunan kaki tanpa badan atas. Letaknya sekitar $4 \mathrm{~m}$ di Ti mur Candi Mahligai. Seluruh bangunan di buat dari bata, berbentuk bujursangkar de ngan tambahan sayap tangga naik berukuran $2,28 \mathrm{~m}$.

5) Pagar Keliling 
Pagar keliling kompleks percandian Muara Takus terbuat dari susunan balok-balok batu pasir (sandstone). Denah pagar berbentuk bujur sangkar dengan ukuran 74 x $74 \mathrm{~m}$. Pe mugaran telah dilakukan, tetapi belum mam pu mengembalikan kondisi pagar seperti se mula. Bagian Utara pagar dahulunya berfung si sebagai pintu gerbang Saat ini yang terting gal hanyalah pondasinya. Lokasinya berada di dekat posko penerimaan tamu Kantor Juru Pelaksana BPCB saat ini.

\section{Bentuk Bangun Datar Segiempat dan Segitiga pada Candi Muaro Takus}

Pagar keliling kompleks percandian Mua ra Takus terbuat dari susunan balok-balok batu pasir (sandstone). Denah pagar berbentuk bujur sangkar dengan ukuran 74 x $74 \mathrm{~m}$. Pemugaran te lah dilakukan, tetapi belum mampu mengembali kan kondisi pagar seperti semula. Bagian Utara pagar dahulunya berfungsi sebagai pintu ger bang Saat ini yang tertinggal hanyalah pondasi nya. Dari hasil wawancara, pembangunan pagar keliling ini memiliki 2 makna dilihat dari sifat keagamaannya. Pertama dari sudut pandang aga ma hindu, pagar keliling ini bermakna pembatas kasta. Dalam agama hindu terdapat 4 kasta yaitu Brahmana, Ksatria, Waisya dan Sudra. Akan te tapi masih ada keberadaan kasta lain yang dipan dang sebelah mata. Ini dibuktikan dengan ada nya bangunan artefak kuno lain yang berada di luar pelataran pagar keliling di kompleks percan dian Muara Takus yang masih belum teridenti fikasi. Kedua dari sudut pandang agama bud dhis, pagar keliling ini murni dipandang sebagai pelindung bangunan yang terdapat didalamnya.

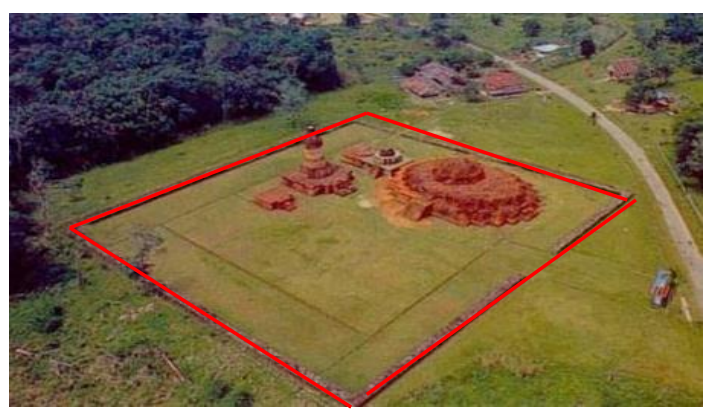

(a)

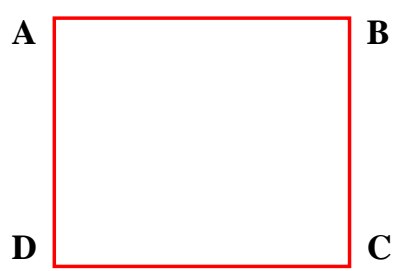

Volume 5| Nomor 1|Mei 2021|Page 77-86 (b)

Gambar 2. a. Pagar keliling pembatas

b. PemodeIan geometri pada pagar keliling pembatas

Pagar keliling pada Gambar 2.a dapat di modelkan secara geometri seperti pada bagian bawah Gambar 2.b. Dari Gambar tersebut, dapat diketahui bahwa pemodelan tersebut berbentuk bangun datar yang memiliki empat sisi. Berdasar kan hal tersebut, peneliti selanjutnya mengana lisis konsep bangun datar segiempat pada pagar keliling tersebut (Gambar 3).

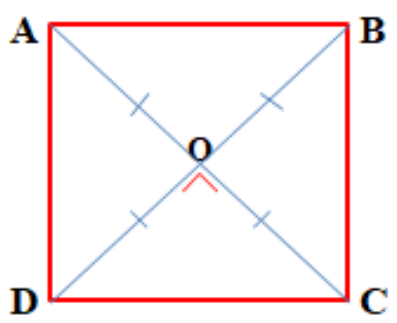

Gambar 3. Konsep persegi pada pagar keIiIing

Berdasarkan analisis pada Gambar 3, ma ka dapat disimpulkan bahwa terdapat konsep per segi pada pagar keliling ini. Adapun sifat-sifat persegi yang dapat ditemukan pada pemodelan pagar keliling sesuai pada Gambar 3, yaitu seba gai berikut.

1) $\mathrm{AB}=\mathrm{BC}=\mathrm{CD}=\mathrm{DA}$

2) $m \angle \mathrm{A}=m \angle \mathrm{B}=m \angle \mathrm{C}=m \angle \mathrm{D}=90^{\circ}$

3) $\mathrm{AO}=\mathrm{OD}=\mathrm{BO}=\mathrm{OC} \Rightarrow \mathrm{AC} \perp \mathrm{BD}$

4) Mempunyai 4 simetri putar dan 4 si metri lipat, sehingga dapat menempati bingkainya dengan 8 cara.

Selain dari berbentuk persegi, dinding can di Muaro Takus juga dapat dimodelkan secara geometri sehingga dapat disimpulkan bahwa bah wa terdapat konsep persegi panjang pada bebera pa dinding Candi Muara Takus (Gambar 4). 


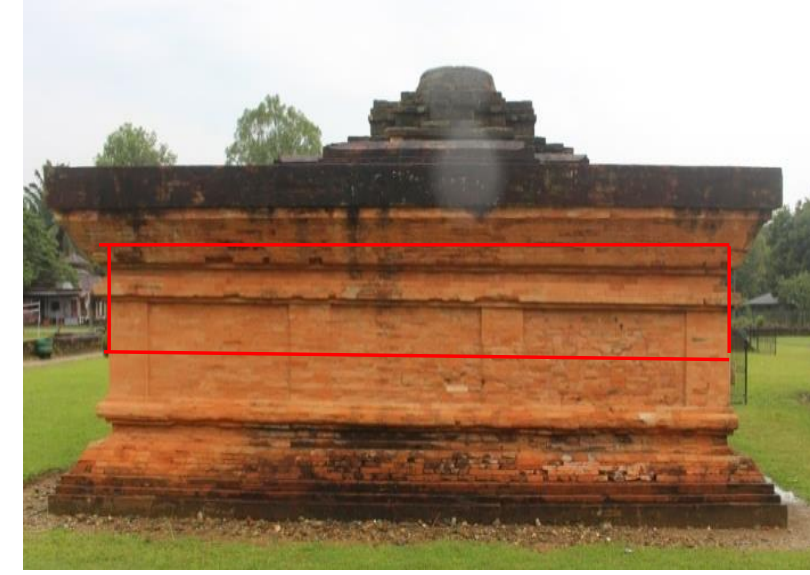

(a)

Gambar 4. a. Dinding Candi Tuo di Kawasan percandian Muara Takus

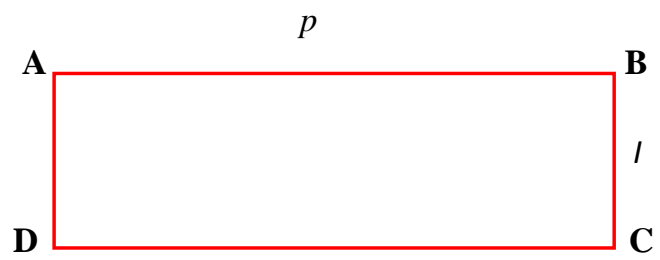

(b)

Gambar 4. b. PemodeIan geometri pada dinding Candi Tuo

Dinding Candi Tuo pada Gambar 4.a da pat dimodelkan secara geometri seperti pada ba gian bawah Gambar 4.b. Dari Gambar tersebut, dapat diketahui bahwa pemodelan tersebut ber bentuk bangun datar yang memiliki empat sisi. Berdasarkan hal tersebut, peneliti selanjutnya menganalisis konsep bangun datar segiempat pa da tersebut dinding candi Tuo (Gambar 5).

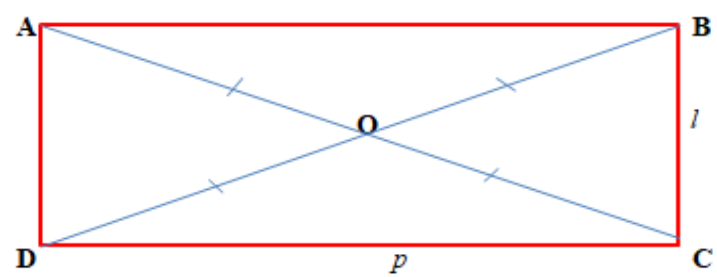

Gambar 5. Konsep persegi panjang pada dinding Candi Tuo

Berdasarkan analisis pada Gambar 5, ma ka dapat disimpulkan bahwa terdapat konsep per segi panjang pada dinding candi Tuo tersebut. Adapun sifat-sifat persegi panjang yang dapat ditemukan pada pemodelan badan candi Tuo se suai pada Gambar 5, yaitu sebagai berikut.
1) $\mathrm{AB} \neq \mathrm{CD} ; \mathrm{BC} \neq \mathrm{AD}$
2) $m \angle \mathrm{A}=m \angle B=m \angle \mathrm{C}=m \angle \mathrm{D}=90^{\circ}$
3) $\mathrm{AO}=\mathrm{OC}=\mathrm{BO}=\mathrm{OD} \Rightarrow \mathrm{AC}=\mathrm{BD}$

4) Mempunyai 2 simetri putar dan 2 simet ri lipat, sehingga dapat menempati bing kainya dengan 4 cara.

Bukan hanya dinding Candi Tuo, bebera pa bagian kawasan percandian Muaro Takus lain nya juga memiliki konsep persegi panjang. Bebe rapa diantaranya, yaitu konsep persegi panjang pada bata kuno penyusun badan candi, dinding candi yang lainnya (Bungsu, Mahligai dan $\mathrm{Pa}$ langka), Undakan Tangga, dan Umpak Batu. Se lain terdapat konsep persegi dan persegi panjang pada kawasan percandian Muaro Takus, dapat ditemukan juga konsep bangun datar segi empat lainnya pada beberapa bagian di kawasan percan dian ini.

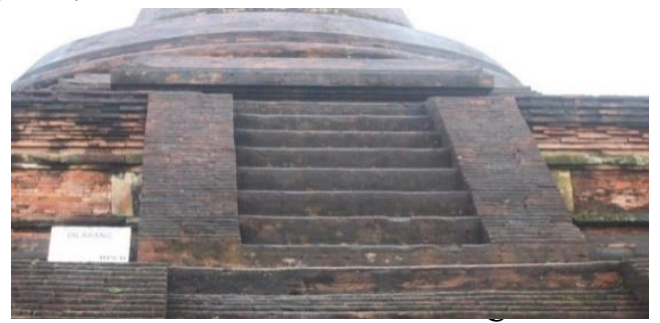

Gambar 6. Undakan Tangga Candi

Gambar 7 berikut menunjukkan bahwa ter dapat konsep jajargenjang pada candi ini.

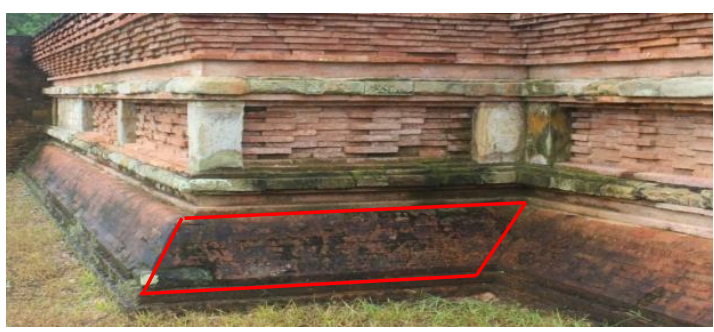

(a)

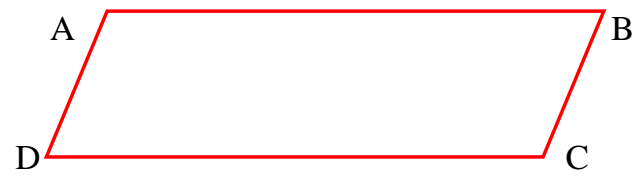

(b)

Gambar 7.a. Kaki candi Tuo di kawasan percandian Muara Takus

b. PemodeIan geometri pada kaki Candi Tuo

Susunan bata kuno pada Gambar 7.a da pat dimodelkan secara geometri seperti pada ba gian bawah Gambar 7.b. Dari Gambar tersebut, dapat diketahui bahwa pemodelan tersebut ber bentuk bangun datar yang memiliki empat sisi. Berdasarkan hal tersebut, peneliti selanjutnya menganalisis konsep bangun datar segiempat pa da susunan bata kuno tersebut (Gambar 8). 


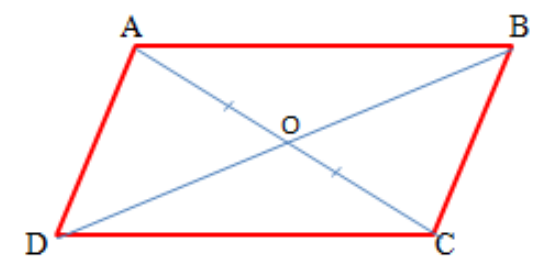

Gambar 8. Konsep Jajargenjang pada kaki Candi Tuo

Berdasarkan analisis pada Gambar 8, ma ka dapat disimpulkan bahwa terdapat konsep jajargenjang pada susunan bata kuno pada kaki candi Tuo tersebut. Adapun sifat-sifat jajargen jang yang dapat ditemukan pada pemodelan su sunan bata kuno kaki candi Tuo sesuai pada Gambar 8, yaitu sebagai berikut.

1) $\mathrm{AB} \neq \mathrm{CD} ; \mathrm{BC} \neq \mathrm{AD}$ (sisi-sisi sehadap)

2) $\angle \mathrm{A}=\angle \mathrm{D} ; \angle \mathrm{B}=\angle \mathrm{C}$ (sudut-sudut sehadap)

3) $m \angle \mathrm{A}+m \angle \mathrm{B}=180^{\circ}$

$m \angle \mathrm{B}+m \angle \mathrm{D}=180^{\circ}$

$m \angle \mathrm{D}+m \angle \mathrm{C}=180^{\circ}$

$m \angle \mathrm{C}+m \angle \mathrm{A}=180^{\circ}$

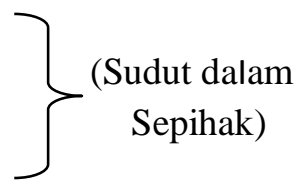

Pada kawasan percandian Muaro Takus ju ga dapat ditemukan konsep bangun datar segi empat lainnya pada beberapa bagian di kawasan percandian ini. Gambar 9 berikut menunjukkan bahwa terdapat konsep trapesium pada candi ini.

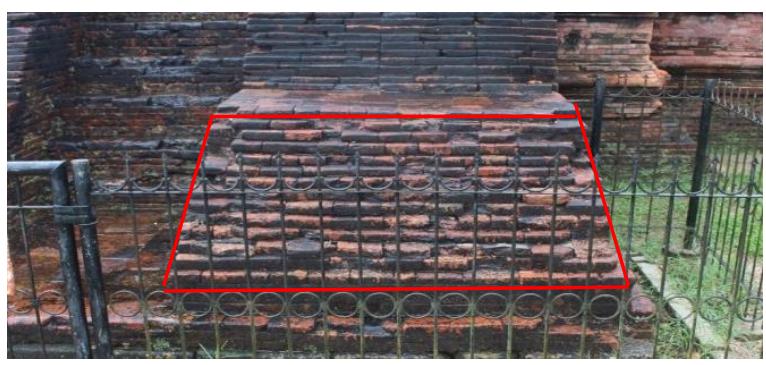

(a)

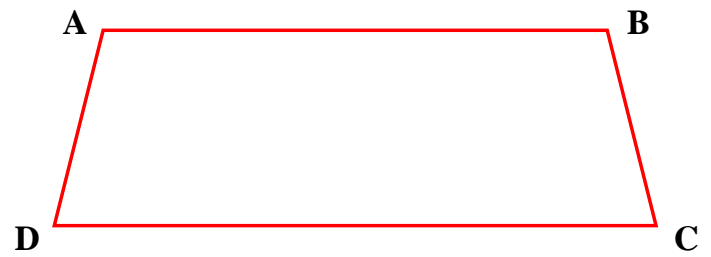

(b)

Gambar 9. a. Susunan bata kuno pada undakan Candi Mahligai

b. PemodeIan geometri pada susunan bata kuno undakan candi MahIigai

Susunan bata kuno pada Gambar 9.a da pat dimodelkan secara geometri seperti pada ba gian bawah Gambar 9.b. Dari Gambar tersebut, dapat diketahui bahwa pemodelan tersebut ber bentuk bangun datar yang memiliki empat sisi. Berdasarkan hal tersebut, selanjutnya dianalisis konsep bangun datar segiempat pada susunan bata kuno tersebut (Gambar 10).

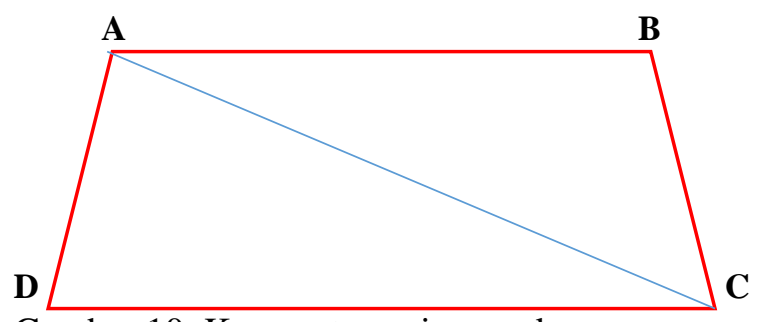

Gambar 10. Konsep trapesium pada susunan batu kuno undakan Candi MahIigai

Berdasarkan analisis pada Gambar 10, ma ka dapat disimpulkan bahwa terdapat konsep tra pesium pada susunan bata kuno tersebut. Ada pun sifat-sifat trapesium yang dapat ditemukan pada pemodelan susunan bata kuno sesuai pada Gambar 10 yaitu sebagai berikut.

1) $\mathrm{AB} / / \mathrm{CD}$ (sepasang sisi)

2) $m \angle \mathrm{A}+m \angle \mathrm{D}=180^{\circ}, m \angle \mathrm{B}+m \angle \mathrm{C}=180^{\circ}$

3) $m \angle \mathrm{A}+m \angle \mathrm{B}+m \angle \mathrm{C}+m \angle \mathrm{D}=360^{\circ}$

Konsep bangun datar segiempat berupa persegi, persegi panjang, jajargenjang dan trape sium merupakan bangun datar segiempat bera turan. Kawasan percandian Muaro Takus tak ha nya memiliki konsep bangun datar segiempat beraturan, peneliti juga menemukan bahwa terda pat konsep bangun datar segiempat tak beraturan pada beberapa bagian candi Muaro Takus.

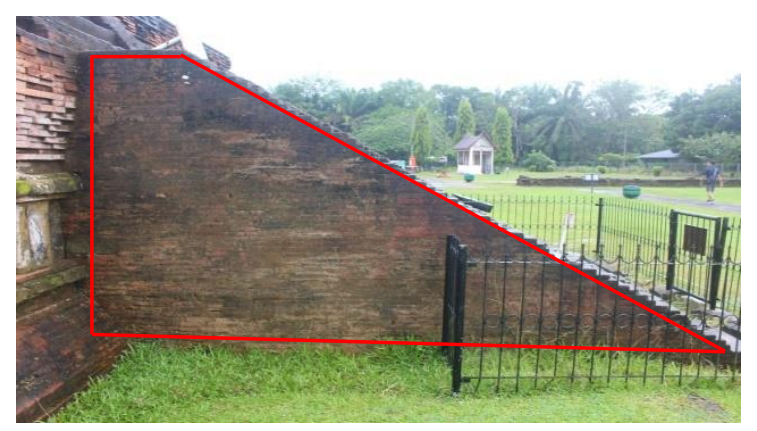

(a)

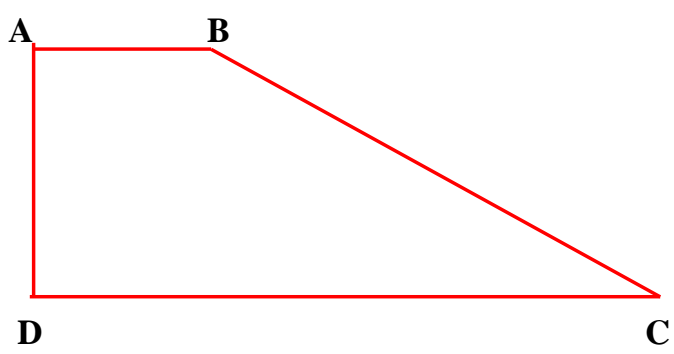

(b) 
Gambar 11. a. Susunan bata pada tangga Candi Tuo

b. PermodeIan geometri susunan batu kuno tangga candi Tuo

Susunan bata kuno pada Gambar 11.a da pat dimodelkan secara geometri seperti pada ba gian bawah Gambar 11.b. Dari Gambar tersebut, dapat diketahui bahwa pemodelan tersebut ber bentuk bangun datar yang memiliki empat sisi. Berdasarkan hal tersebut, selanjutnya dianalisis konsep bangun datar segiempat pada susunan bata kuno tersebut. Berdasarkan analisis pemo delan pada Gambar 11, maka dapat disimpulkan bahwa terdapat konsep segiempat tak beraturan pada susunan bata kuno tersebut. Adapun sifatsifat segiempat tak beraturan yang dapat ditemu kan pada pemodelan susunan bata kuno sesuai pada Gambar 11 yaitu sebagai berikut.

1) $\mathrm{AB} \neq \mathrm{BC} \neq \mathrm{CD} \neq \mathrm{AD}$

2) $m \angle \mathrm{A} \neq m \angle B \neq m \angle C \neq m \angle \mathrm{D}$

Di kawasan percandian Muara Takus, ti dak hanya menemukan konsep bangun datar se giempat tapi juga ditemukan konsep bangun da tar segitiga. Ini terlihat dari bentuk susunan bata kuno pada tangga Candi Bungsu, terlihat pada Gambar 12.

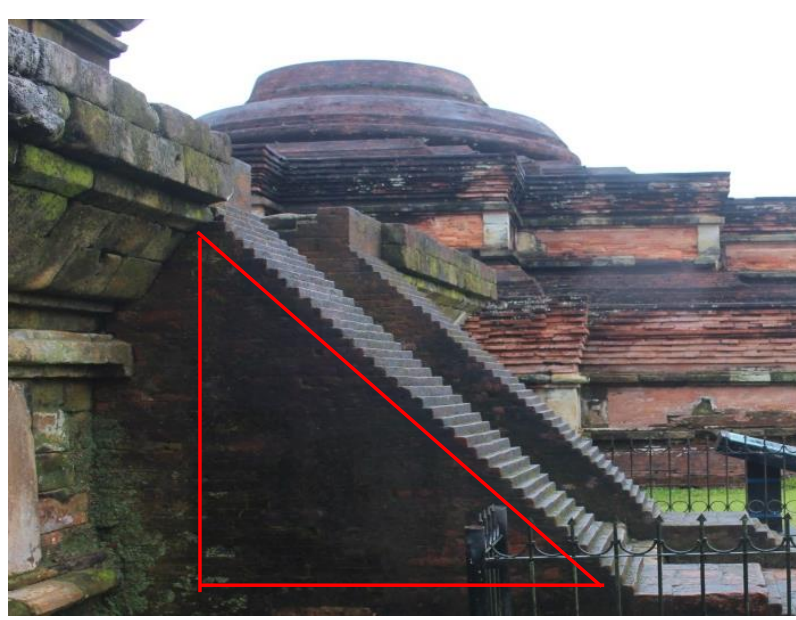

(a)

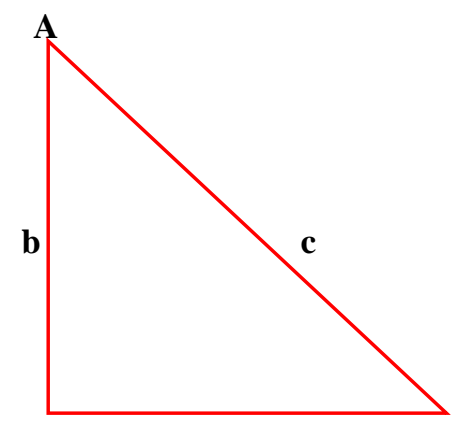

Volume 5| Nomor 1|Mei 2021|Page 77-86
C

a

B

(b)

Gambar 12. a. Susunan bata pada tangga Candi Bungsu

b. PemodeIan geometri susunan bata kuno pada tangga Candi Bungsu

Susunan bata kuno pada Gambar 12.a da pat dimodelkan secara geometri seperti pada ba gian bawah Gambar 12.b. Dari Gambar tersebut, dapat diketahui bahwa pemodelan tersebut ber bentuk bangun datar yang memiliki tiga sisi. Berdasarkan hal tersebut, peneliti selanjutnya menganalisis konsep bangun datar segitiga pada susunan bata kuno tersebut. Berdasarkan analisis pemodelan pada Gambar 12, maka dapat disim pulkan bahwa terdapat konsep segitiga siku-siku pada susunan bata kuno tersebut. Adapun sifatsifat segitiga siku-siku yang dapat ditemukan pada pemodelan susunan bata kuno sesuai pada Gambar 12 yaitu sebagai berikut.

1) $\mathrm{AB} \perp \mathrm{BC}$

2) $m \angle \mathrm{B}=90^{\circ}, m \angle \mathrm{A}+m \angle \mathrm{C}=90^{\circ}$

3) Teorema Phytagoras: $c^{2}=a^{2}+b^{2}$

\section{Bentuk lingkaran pada Candi Muaro Takus}

Candi Tua merupakan bangunan yang ter besar di dalam kompleks percandian Muara Ta kus. Bangunan ini nyaris menempel di sisi utara Candi Bungsu dengan jarak hanya sekitar 22 $\mathrm{cm}$. Bangunan terbesar dikompleks percandian Muara Takus dan merupakan bangunan masif (tidak memiliki ruang) yang ditempatkan diatas kaki bertingkat tiga dengan ukuran $32,80 \mathrm{~m} \times$ $21,80 \mathrm{~m}$ dan tinggi $8,50 \mathrm{~m}$, dengan bagian pa ling atas berbentuk stupa.

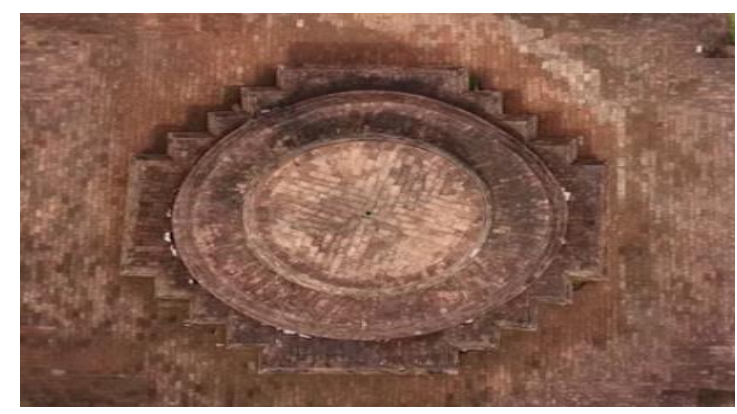

(a)

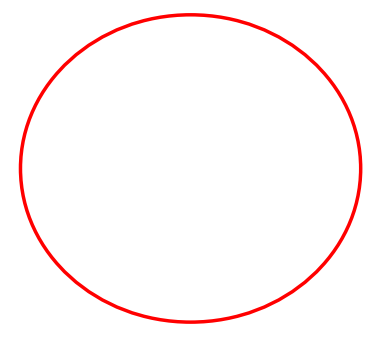


(b)

Gambar 13. a. Stupa pada Candi Tuo

b. PermodeIan geometri pada Stupa Candi Tuo

Stupa Candi Tuo pada Gambar 13.a dapat dimodelkan secara geometri seperti pada bagian bawah Gambar 13.b. Dari Gambar tersebut, da pat diketahui bahwa pemodelan tersebut berben tuk sebuah lingkaran. Berdasarkan hal tersebut, peneliti selanjutnya menganalisis konsep lingkar an pada stupa tersebut. Berdasarkan analisis pe modelan pada Gambar 13, maka dapat disimpul kan bahwa terdapat konsep lingkaran pada stupa tersebut. Adapun sifat-sifat lingkaran yang dapat ditemukan pada pemodelan stupa sesuai pada Gambar 13, yaitu sebagai berikut.

1) Memiliki simetri lipat dan simetri putar tak terhingga

2) Tidak memiliki titik sudut

3) Memiliki satu sisi

Bukan hanya stupa yang ada di Candi Tuo, beberapa bagian kawasan percandian Mua ro Takus lainnya juga memiliki konsep ling karan. Beberapa diantaranya yaitu konsep ling karan pada bata kuno penyusun stupa di Candi Mahligai dan candi Bungsu.

\section{Refleksi dan Dilatasi}

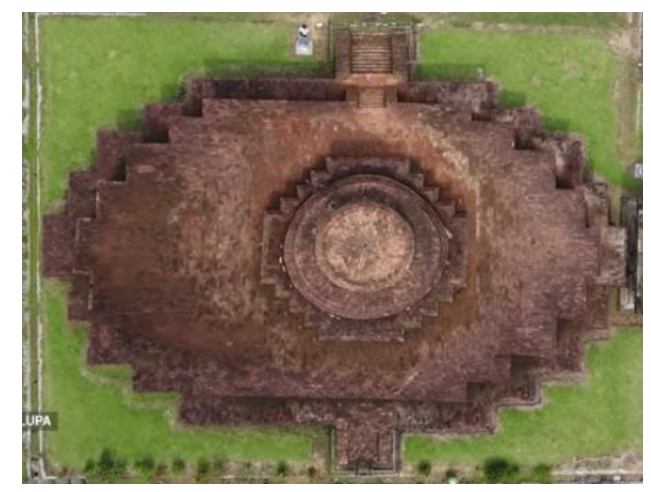

Gambar 14. Candi Tuo (Tampak dari atas)

Bangunan Candi Tua menjadi bangunan utama pertama yang ditemui jika wisatawan. $\mathrm{Wu}$ jud bangunan utuh dan selesai dipugar. Struktur kaki bangunan hasil pemugaran memiliki wujud empat persegi panjang pada tingkat I dengan ba nyak penampil. Jumlah sudut luarnya adalah 24 buah, termasuk sudut tangga naik. Bangunan ini memiliki dua (2) buah tangga naik di sisi Barat dan di sisi Timur untuk mencapai puncak stupa.
Pada Gambar 14 tersebut, dapat diketa hui bahwa Candi Tuo tersebut memuat konsep refleksi pada bayangan dua buah anak tangga pa da sisi timur dan sisi barat. Selain itu juga dite mukan konsep dilatasi pada tingkat I dan tingkat II. Terlihat bahwa tingkat II merupakan bangun an bayangan yang diperkecil dari tingkat I.

\section{Garis dan Sudut}

Pada Gambar 15 tersebut, dapat diketahui bahwa pada Candi Tuo tersebut memuat konsep garis dan sudut, dimana terlihat beberapa buah garis yang sejajar, berpotongan, berhimpit, dan juga bersilangan.

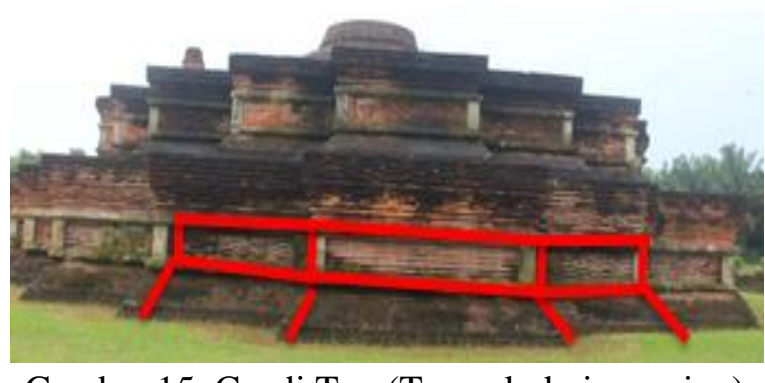

Gambar 15. Candi Tuo (Tampak dari samping)

Selain itu, terlihat hubungan antar sudut, yaitu apabila dua buah garis sejajar dipotong oleh se buah garis.

\section{KESIMPULAN}

Berdasarkan hasil dan pembahasan yang telah dipaparkan sebelumnya, dapat disimpulkan bahwa hasil penelitian menunjukkan dalam akti vitas pembangunan candi Muara Takus terdapat unsur dan konsep matematika yang digunakan. Tanpa mempelajari teori tentang konsep matema tika tersebut, masyarakat Hindu-Budhis telah me nerapkan konsep matematika dalam kehidupan sehari-hari dengan menggunakan etnomatemati ka. Terbukti adanya bentuk etnomatematika yang tercermin melalui hasil aktivitas membuat rancangan pembangunan candi Muara Takus. Pa da kawasan percandian ini, dapat ditemukan kon sep bangun datar segiempat (persegi, persegi panjang, jajargenjang, trapesium dan segiempat tak beraturan) dan segitiga (segitiga siku-siku), lingkaran, refleksi \& dilatasi, serta garis dan su dut pada beberapa bagian candi. Guru dapat me manfaatkan konsep-konsep matematika pada candi Muaro Takus sebagai sumber belajar mate matika yang bersifat konkret. Objek etnomatema tika yang ada di sekitar kita juga dapat dimanfa atkan untuk pembelajaran inovatif. 


\section{DAFTAR PUSTAKA}

Arikunto, S. 2013. Prosedur Penelitian. Jakarta: Rineka Cipta.

Achor, E. E., dkk. 2009. Effect of Ethnoma thematics Teaching Approach on Senior Secondary Students' Achievement and Re tention in locus.

D'Ambrosio, U. 1985. Ethnomathematics and its place in the history and pedagogy of mathematics. For the learning of mathe matics, 5(1), 44-48.

Fajriyah, E. 2018. Peran Etnomatematika Ter kait Konsep Matematika Dalam Mendu kung literasi. Jurnal Prisma 1, Prosiding Seminar Nasional Matematika, 1, 114119.

Fathani, A. H. 2009. Matematika: Hakikat dan logika. Yogyakarta: Ar-Ruzz Media.

Hardiarti, S. 2017. Etnomatematika: Aplikasi Bangun Datar Segiempat Pada Candi Mua ro Jambi. Jurnal Aksioma, 8 (2), 99-110.

Jayanti, T. D., \& Puspasari, R. 2020. Eksplorasi Etnomatematika pada Candi Sanggrahan Tulungagung. Jurnal JP2M, 6 (2), 53-66

Peraturan Menteri Pendidikan dan Kebudayaan Nomor 70 Tahun 2013. Kerangka Dasar dan Struktur Kurikulum Sekolah Mene ngah Kejuruan / Madrasah Aliyah Keju ruan. Jakarta: Menteri Pendidikan dan Kebudayaan Republik Indonesia.
Rahmawati, Y., \& Muchlian, M. 2019. Eks plorasi Etnomatematika Rumah Gadang Minangkabau Sumatera Barat. Jurnal Ana lisa, 5 (2), 124-136.

Risdiyanti, I., \& Prahmana, R. C. I. 2020. Ethno mathematics (Teori dan Implementasinya: Suatu Pengantar). Bantul: UAD Press.

Soedewo, E., dkk. 2015. Berita Penelitian Arkeologi Jejak Peradaban Hindu-Buddha Di Kawasan Kompleks Percandian Muara Takus Kabupaten Kampar, Provinsi Riau. Medan: Balai Arkeologi Medan.

Sulistyani, A., dkk. 2020. Pengembangan Pariwi sata Berbasis Ethno-Heritage Di Kawasan Percandian Muara Takus Kabupaten Kam par Provinsi Riau. Prosiding Seminar Na sional Riset Teknologi Terapan.

Utami, dkk. 2020. Etnomatematika: Eksplorasi Candi Borobudur. Jurnal JPEM, 6 (1), 1326

Wahyuni, A., dkk. 2013. Peran Etnomatematika dalam Membangun Karakter Bangsa, ma kalah dipresentasikan dalam seminar na sional matematika dan pendidikan mate matika dengan tema "Penguatan Peran Matematika dan Pendidikan Matematika untuk Indonesia yang lebih Baik" pada tanggal 9 November 2013 di Jurusan Pendidikan Matematika FMIPA UNY. 